\title{
Perspectives on using remotely-sensed imagery in predictive veterinary epidemiology and global early warning systems
}

\author{
Vincent Martin ${ }^{1}$, Lorenzo De Simone 2 , Juan Lubroth ${ }^{2}$, Pietro Ceccato ${ }^{3}$, Véronique Chevalier ${ }^{4}$ \\ ${ }^{1}$ Emergency Centre for the Control of Transboundary Animal Diseases (ECTAD), FAO, Beijing, People's \\ Republic of China; ${ }^{2}$ Animal Health Service, Infectious Disease Group of FAO, Rome, Italy; ${ }^{3}$ International \\ Research Institute for Climate and Society, the Earth Institute, Columbia University, Palisades, New York, \\ USA; ${ }^{4}$ Centre de Coopération Internationale en Recherche Agronomique pour le Développement (CIRAD), \\ Montpellier, France
}

\begin{abstract}
Recent disease epidemics and their spread around the world have illustrated the weaknesses of disease surveillance and early warning systems (EWS), both at national and international levels. These diseases continuously threaten the livestock sector on a worldwide basis, some with major public health impact. EWS and accurate forecasting of new outbreaks of epidemic livestock diseases that may also affect wildlife, and the capacity for spread of such diseases to new areas is an essential pre-requisite to their effective containment and control. Because both the geographical and seasonal distribution of many infectious diseases are linked to climate, the possibility of using climaterelated environmental factors as predictive indicators, in association with regular disease surveillance activities, has proven to be relevant when establishing EWS for climate-related diseases. This article reviews the growing importance of using geographical information systems in predictive veterinary epidemiology and its integration into EWS, with a special focus on Rift Valley fever. It shows that, once fully validated in a country or region, this technology appears highly valuable and could play an increasing role in forecasting major epidemics, providing lead time to national veterinary services to take action to mitigate the impact of the disease in a cost-effective manner.
\end{abstract}

Keywords: remote sensing, early warning system, trans-boundary animal disease, Rift Valley fever.

\section{Introduction}

At the end of the $19^{\text {th }}$ century, a pandemic of rinderpest, also known as cattle plague, decimated the livestock and wildlife populations of Africa. It is estimated that some $90 \%$ of the cattle population at that time was eliminated by the plague. The $20^{\text {th }}$ century witnessed a steady decline in the incidence and extent of epizootic in industrialised countries, thanks to developments in technology, farming industry, animal health services and the dedicated

Corresponding author:

Vincent Martin

Emergency Centre for the Control of

Trans-boundary Animal Diseases (ECTAD)

FAO Representation in China, Jianguomenwai 4-2-151

100600 Beijing, People's Republic of China

Tel. +8610 6532 2835; Fax +86106532 5042

E-mail: Vincent.Martin@fao.org application of adequate resources. However towards the end of the $20^{\text {th }}$ century and spanning in the new millennium, epidemic livestock diseases have been showing an alarming tendency to spread through inter alia increased mobility of people, expansion of urban areas encroaching on adjacent environments, commerce of goods and livestock, wildlife contraband, changes in farming systems, climatic changes and weakened livestock health services.

In general, most of these diseases are endemic in developing countries, causing constant attrition and periodic, dramatic losses, which invariably retard progress in development programmes such as the Special Programme for Food Security. For example, African swine fever in West Africa resulted in the loss of about $50 \%$ of the standing pig population, while in Malaysia an outbreak of Nipah virus resulted in a $45 \%$ loss of that country's swine and in 
Hong Kong an outbreak of highly pathogenic avian influenza required a complete depopulation and restocking of poultry.

As long as trans-boundary and zoonotic diseases remain endemic in developing countries, the animal protein food security of these countries and the economic welfare of those involved in production remain highly compromised. These diseases are also a severe constraint to trade, both nationally and internationally. Such animal diseases thus exclude poor communities and many developing countries from the process and potential benefits of globalisation with respect to trade in healthy livestock and their products.

There is also the increasing challenge of emerging diseases and new manifestations of existing diseases, through changing epidemiological circumstances, climate change and changing pattern of livestock husbandry and open trading systems. One of these newly emerging diseases is Rift Valley fever (RVF). RVF was first identified in 1931 after heavy seasonal rains in the Rift Valley in Kenya. The significance of the disease lies in its public health impact and the economic losses resulting from the cessation of trade once RVF virus activity is identified. This has been especially highlighted with the prolonged import bans from countries in the Arabian Peninsula to the countries of the Horn of Africa where RVF has been registered, causing great hardship to the livestocktrade based communities of the Horn.

In parts of East Africa known to be prone to RVF epidemics, remotely-sensed rainfall and vegetation measurements have been integrated into regional and global early warning systems (EWS) and used to predict RVF before it reaches epidemic proportions. The ultimate goal of such systems is to safeguard sustained livestock production and have developing countries participate legitimately in local, regional and international trade.

EWS as the weakest link in disease prevention and control activities

Early detection, epidemiological analysis and reporting of cases are among the weakest links in the chain of actions necessary to prevent the introduction of trans-boundary animal diseases (TADs), control of epidemics and elimination of the disease. EWS is identified as all disease initiatives, which would be based predominantly on epidemiological surveillance, that would lead to improved awareness and knowledge of the distribution of disease or infection and that might permit forecasting of the further evolution of an outbreak (EMPRES Expert Consultation, 1996).

There have been many instances where outbreaks of serious epidemic livestock disease in new areas have not come to the attention of central veterinary authorities for several weeks or even months. The diseases have thus been able to spread unchecked, causing unnecessary production losses and making control and elimination of the disease more difficult and expensive, or perhaps even impossible. Failure to report new disease occurrences to neighbouring countries and trading partners either directly or through international organisations such as the World Organization for Animal Health (OIE) and the Food and Agriculture Organization (FAO), has meant that other countries were unable to take the necessary steps to prevent its introduction. Furthermore, as observed during the RVF epizootic in the Horn of Africa in 1997-1998, the negative impact of TADs on trade is also of critical importance on food security matters and human livelihood. Currently, many countries are removed from participation in formal livestock markets - or were simply never able to enter it - because a disease has occurred on their soil. A potential lucrative trade may never have been developed because it was prejudiced from the start by disease occurrence - an impact that may never have been generally achieved. TADs are, therefore, not only a threat to household food security, but they are also a barrier to enter into formal trade, and therefore an impediment to economic and livestock development, poverty alleviation and the public good. Financial return to farmers from livestock trade is a fundamental requirement for livestock development to proceed.

To respond to the lack of EWS in dealing with livestock diseases, FAO developed and launched the 
Emergency Prevention System for Trans-boundary Animal and Plant Diseases and Pests (EMPRES) in 1994. This programme emphasises the prevention of emergencies due to trans-boundary, epidemic diseases of livestock that are of significant economic, trade and/or food security importance for a considerable number of countries which can easily spread to other countries and reach epidemic proportions and where control/management, including exclusion, requires co-operation between several countries.

The EMPRES vision is "to promote the effective containment and control of the most serious epidemic livestock diseases as well as newly emerging diseases by progressive elimination on a regional and global basis through international co-operation involving EWS, early/rapid-reaction, enabling research and coordination".

From a broader perspective, the ultimate goal of the EWS component of the EMPRES programme has been to enhance global, risk-based surveillance in order to improve specific knowledge of where TADs occur and to use this information to generate sound intervention strategies for their containment and control.

At the veterinary-public health interface, the FAO, together with the OIE and the World Health Organization (WHO), have joined their efforts and respective EWS to create the Global EWS for livestock diseases (GLEWS). The concept was initially raised during the expert consultation of the EMPRES programme in July 1996, formalised and endorsed by the panel of experts reviewing the programme. After several years of concept development, the GLEWS system has now become operational and officially launched in July 2006.

\section{Forecasting RVF epidemics using remote sensing satellite imagery}

\section{Background}

The RVF virus belongs to the genus Phlebovirus, of the Bunyaviridae family. Clinical manifestations are characterised by fever, pantropic haemorrhages, or abortion for humans and ungulates. Its geographical distribution is usually confined to Africa, with two exceptions in Saudi Arabia and Yemen in the year 2000 which clearly demonstrate the potential of the virus to expand and spread to new continents. In the face of climate change, and the experience of other arboviruses, such as bluetongue (Ducheyne et al., 2007) and Chickingunya in Europe or West Nile virus in Europe and America, RVF may well expand its geographical occurrence.

Epidemics of RVF have occurred in southern and eastern Africa at irregular intervals. These epidemics have been associated with above average rainfall after a period of drought and the presence of susceptible exotic breeds of livestock. The occurrence of RVF can be endemic or epidemic, depending on the climatic and vegetation characteristics of different geographic regions. In the high rainfall forest zones in coastal and central African areas it is reported to occur in endemic cycles which are poorly understood. It is usually detected either by serological studies, or by the appearance of sporadic human disease cases. In the much drier bush savannah grasslands and semi-arid zones, which are characteristic for the Horn of Africa, epidemic RVF has manifested itself only a few times in the past 50 years, in 1961-1962, 1982-1983, 1989, in 19971998 and 2006-2007. RVF epizootics have also been reported in the Sudan, at the Gezira irrigation scheme in 1973-1974, in Egypt in 1977-1979 and 1993-1994, where hundreds of thousands of human cases were reported with at least 600 deaths. A highly fatal haemorrhagic syndrome was described in Egypt and also an ocular syndrome with macular degeneration and in some cases leading to blindness. There were enormous losses in sheep, goats and cattle populations, with abortion in camels.

In East Africa, historical information has shown that pronounced periods of RVF virus activity have occurred during periods of heavy, widespread and persistent rainfall now associated as El Niño events triggered by large-scale changes in sea surface temperature in the Pacific Ocean with manifestations in climate anomalies at regional scale. Because climat- 
ic conditions that favor the breeding of the mosquito vectors of RVF tend to occur over large areas, there is a tendency for outbreaks to occur simultaneously in adjacent countries. Similarly, the onset of drier or cooler weather that suppresses vector activity is associated with the decline of epidemics.

In West Africa, a large RVF outbreak occurred in the human population in 1987-1988 (Saluzzo et al., 1987; Ksiazek et al., 1989; Lancelot et al., 1990), and was thought to be causally linked with the newly constructed dam on the Senegal River at the Mauritania-Senegal border (Jouan et al., 1988). The increase in the level of the water table, upstream of the lake established by the dam, created extensive new breeding habitats for mosquitoes. Abortions were reported in small ruminants and camels, with some mortality in the young animals. In humans, a higher frequency of neurological signs was reported in than in previous epidemics. A further episode of virus activity in the region, first identified again through evidence of human disease, occurred in 1998, in the province of Hodh El Gharbi, south-east of Mauritania (Nabeth et al., 2001). In 2003, high level of viral circulation were also detected in the Ferlo (northen Senegal) characterized as semi-arid area with a dense temporary pond system. This circulation was shown to be linked to the pond type (slope, vegetation cover, etc.) as well as the rainfall pattern (level, rhythm) (Chevalier et al., 2005).

The 1997-1998 epidemic in East Africa has been considered one of the most devastating epidemics of RVF in the region. Associated with torrential rains (60-100 times the seasonal average) which occurred across most of East Africa from late October 1997 to January 1998, resulted in the worst flooding in the Horn of Africa since 1961 (CDC 1998; WHO 1998). In December 1997, unexplained deaths were reported in people in the north eastern province of Kenya and in southern Somalia. Surveys confirmed the presence of a haemorrhagic syndrome in humans which included fever with mucosal or gastrointestinal bleeding. Some patients with this syndrome were shown to have acute infection with RVF virus. RVF cases were also confirmed in people in the north eastern, central, eastern, and Rift Valley provinces of Kenya, and in the Gedo, Hiran, and Lower Shabelle provinces of Somalia (CDC 1998; WHO 1998). Livestock losses of up to $70 \%$ in sheep and goats, and $20-30 \%$ of cattle and camels, were also reported and surveys confirmed that RVF was present in livestock.

At the end of 2006 and early 2007, RVF reemerged in its epidemic form in Kenya, first in the Garissa district and then with further outbreaks reported in other parts of Kenya and Tanzania, urging the governments to take stringent control measures in an attempt to mitigate the impact of the disease in both human and animals. Other epidemics are expected in the future and the disease could eventually move northwards into new ecosystems and cause severe losses.

The application of remote sensing satellite imaging (RSSI) technology in RVF monitoring systems

In parts of East Africa known to be prone to RVF epidemics, remotely-sensed rainfall and vegetation measurements have been used to predict RVF before it reached epidemic proportions. Data sets used in these predictions include satellite vegetation index, cold cloud duration (CCD), and inter tropical convergence zone correlated with climatic changes (Davies and Martin, 2003). Measurements from the Advanced Very High Resolution Radiometer sensor (AVHRR) on-board polar-orbiting satellite series operated by the National Oceanographic and Atmospheric Administration (NOAA), are used to generate the normalized difference vegetation index (NDVI). NDVI is calculated from surface reflectance measurements in the red (channel 1, 0.58-0.68 $\mu \mathrm{m}$ ) and infrared (channel 2, 0.725 to $1.1 \mu \mathrm{m}$ ) portions of the electromagnetic spectrum to describe the relative amount of green biomass as follows: NDVI = (channel 2 - channel 1)/(channel $2+$ channel 1).

In East Africa, vegetation index maps have been used together with ground data in monitoring vector populations and RVF viral activity, establishing a correlation between these two parameters. Indeed, 
a detailed analysis was made with virus isolation data over a 25-year period and NDVI records for the study area (Linthicum et al., 1987). As the water table rises to the point where flooding may occur, the NDVI ratio approaches 0.43 to 0.45 (Linthicum et al., 1987). This point was reached during each of the epizootic periods in the study period. However, the use of a threshold value to evaluate favourable conditions and predict epidemic must be used with caution. NDVI values may vary with the sensor instrument used, atmospheric and observation conditions. Observing the same vegetation with different sensors provides different NDVI value ranges. It is thus necessary to observe trends in NDVI and analyse how anomalies create good conditions for the outbreak of epidemics.

The main advantage of using remote sensing for prediction of RVF occurrence in East Africa is the relatively low cost of the system used for analysis. It is readily available on a country and regional basis, and its use may allow for preventive measures to be taken such as the vaccination of susceptible livestock and mosquito larval control methods (Linthicum et al., 1990, 1999). Predictive models were greatly improved during the past decade by the addition of Pacific and Indian ocean sea surface temperature anomalies measurements, together with the rainfall and NDVI data. An accuracy of 95$100 \%$ was estimated for the prediction of Kenyan epizootics of RVF, with a lead time of 2 to 5 months (Linthicum et al., 1999). These studies showed the potential of using RSSI in monitoring periods of RVF virus activity and predicting epidemics (Linthicum et al., 1987; Anyamba et al., 2002). The technology has been used extensively by the FAO to warn countries facing an increased risk of the disease. Unfortunately, these associations have not been adequately defined beyond East Africa largely because of inadequate ground data on viral activity and even there, further studies are required.

In Senegal (West Africa), a local scale landscape approach is being developed to test some ecological parameters to identify risk areas. A very high spatial resolution remote sensing image (2.4 $\mathrm{m}$ resolution) provided by the Quickbird sensor was used to characterize the temporary ponds and the vegetation around. Object-based image-processing techniques, were applied to provide a pond map, a vegetation map around the ponds and a general land use map. These maps have been used to calculate three landscape indexes assumed to be linked to Aedes biology:

(i) landscape closure index calculated within a 100, 500 and $1000 \mathrm{~m}$ radius buffer around the pond;

(ii) water vegetation coverage index; and

(iii) pond density index corresponding to the number of neighbouring ponds within a radius of $1 \mathrm{~km}$.

Statistical analyses were performed using logisticregression mixed models (LMRR) coupled with serologic incidence data collected in 2003 (Chevalier et al., 2005) as a result with the indexes as explanatory variables. The landscape closure variable was correlated with higher serologic incidence. These first results highlight the potential of high resolution remote sensing to characterize the landscape structure at a relevant scale. When validated, these results could be extrapolated to the whole region and used to target the surveillance on risky ponds (Soti et al., 2007).

\section{FAO's role in RVF global monitoring}

The EMPRES livestock programme has been monitoring the evolution of RVF epidemics for over 10 years in key ecosystems of East and West Africa. Combining national surveillance efforts with the expertise of recognised centres of excellence, EMPRES has played a key role in developing and validating a RVF EWS in East and West Africa, using the most advanced technology to detect the early signs of the disease and warn countries in advance of its possible emergence.

Through its EMPRES- $i$ information platform, data are gathered and integrated for global and regional risk assessment studies. Risk assessment results are disseminated to recipient countries, regional and international organizations and key stakeholders in the form of bulletins and alerts to 
communicate with national veterinary services in the expectation that mitigation activities would be implemented through the advice provided, as well as to the wider scientific community.

At FAO headquarters, near real-time climatic data such as rainfall estimate and NDVI indices obtained from ARTEMIS ${ }^{1}$ are collected and processed using the FAO developed Windisp 3.0 software. Risk maps are produced by calculating vegetation index and rainfall anomalies comparing current conditions with long-term mean conditions. Resulting maps show areas experiencing above normal rainfall, a predominant factor shown to be associated with the emergence of epizootics in East Africa. Other partner institutions such as the NASA Goddard Space Flight Center produce RVF monthly risk maps based on the persistence of NDVI anomalies in RVF epidemicprone regions and are used by the EMPRES group in their qualitative risk assessment studies.

Based on the combined results of national surveillance programmes (i.e. serological monitoring of sentinel herds or flocks located in high RVF risk areas), seasonal climate forecasts and NDVI anomalies, RVF risk assessments are produced and alerts delivered to countries when climatic conditions prevailing in the region are conducive to an epidemic situation.

Were the EWS functional in 2006 for the prediction of RVF epidemics in Kenya?

Current evidence suggests that RVF virus in subSaharan Africa is maintained in inter-epidemic periods primarily by transovarial transmission in aedine mosquitoes. Aedine mosquitoes are zoophilic, floodwater-breeding species that oviposit in the top $50 \mathrm{~mm}$ of soil at the edge of standing water. Their eggs can resist desiccation for long periods and do

\footnotetext{
${ }^{1}$ In order to assist these programmes, FAO established in 1988 the Africa Real Time Environmental Monitoring System (ARTEMIS), with the objective of providing a routine flow of satellite imagery in near real-time indicating the status of the growing season and vegetation development over Africa.
}

not hatch until the next water inundation following prolonged rainfall or flooding. Aedine mosquitoes are thought to maintain a low level of viral transmission to livestock, with epidemics triggered by above-average rainfall that leads to a rapid increase in vector numbers. Once infection has been amplified in livestock, secondary epidemic vectors such as culicine and anopheline mosquitoes that breed in semi-permanent pools of water can become competent vectors in virus transmission.

Such conditions were present by the end of 2006 when heavy rainfall was observed in areas previously affected by drought conditions. Indeed, favourable eco-climatic conditions were building up and intensified from October 2006 through January 2007, providing suitable conditions for the multiplication of mosquitoes at their breeding sites in known epidemic-prone areas of Kenya. A drastic increase of NDVI anomalies (index difference between a given month and the average calculated over an 8-year period) was observed in most parts of Kenya, southern Ethiopia, southern Somalia and Tanzania in areas that had received above-average precipitations (Figs. 1-4) from October through January. These anomalies depicting areas of increased risk of RVF outbreaks were as high as during the 1997-1998 epidemic, forecasting a possible repeat of the most devastating epidemic of RVF in the Horn of Africa.

NDVI indices were extracted from spot vegetation sensor for the North-Eastern province of Kenya (Fig. 5) from March 1998 to date and analysed using the FAO-developed Windisp software to study the deviation from the mean of this indicator. Figure 6 shows that negative NDVI anomaly values were followed by periods of high positive NDVI anomaly values towards the end of 2006. The same pattern was observed in 1997-1998. The high positive NDVI anomaly values correspond to an increase of vegetation activity which is related to wetter than normal conditions.

Three-month seasonal forecasts issued by the International Research Institute for Climate and Society (IRI) for the period December-JanuaryFebruary also forecasted heavy rainfall for this peri- 


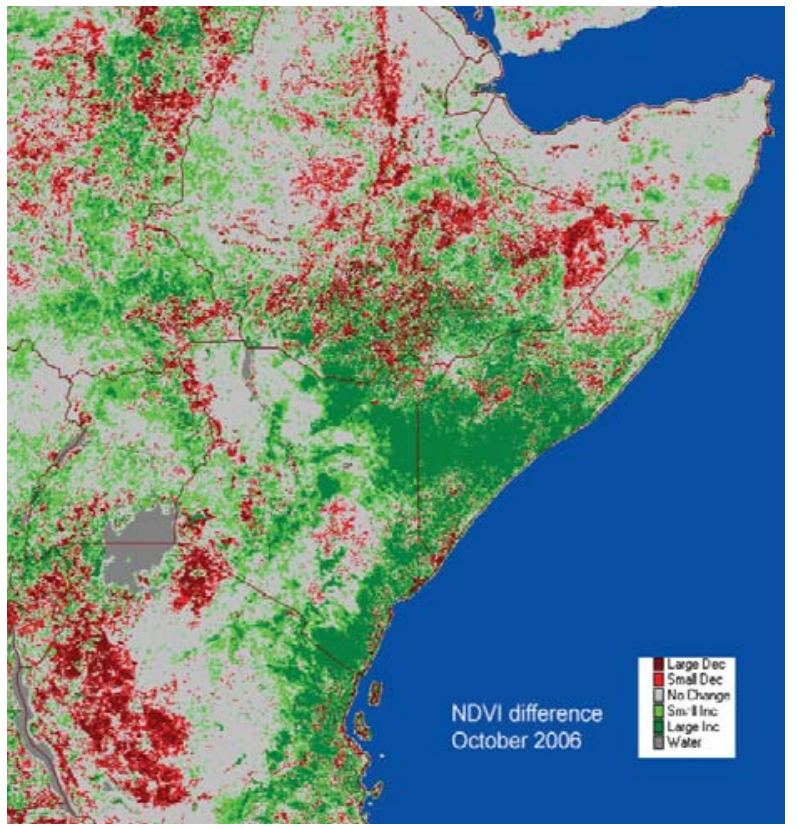

Fig. 1. NDVI anomalies in October 2006.

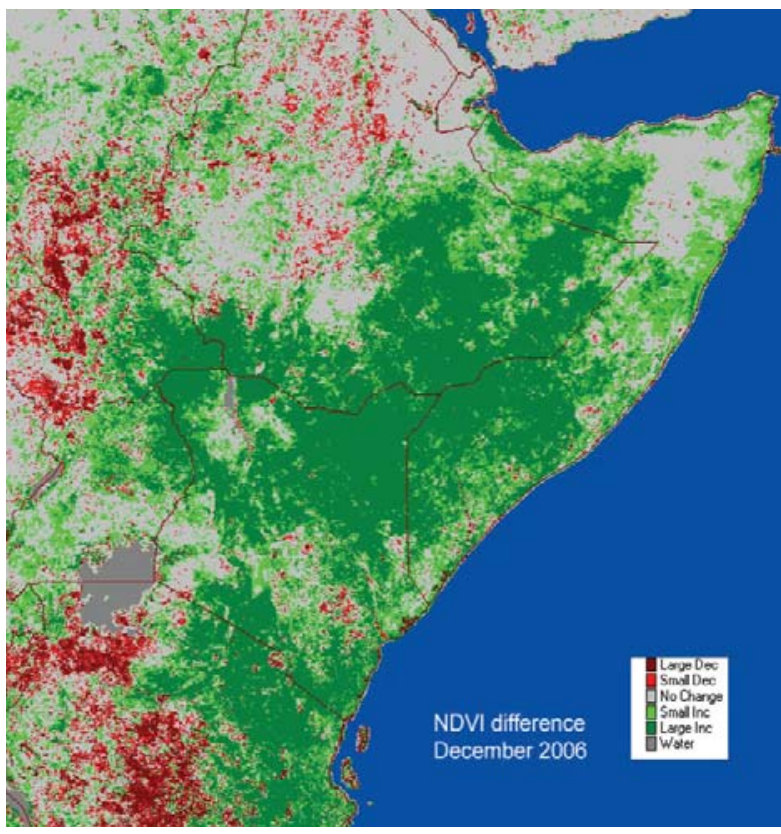

Fig. 3. NDVI anomalies in December 2006.

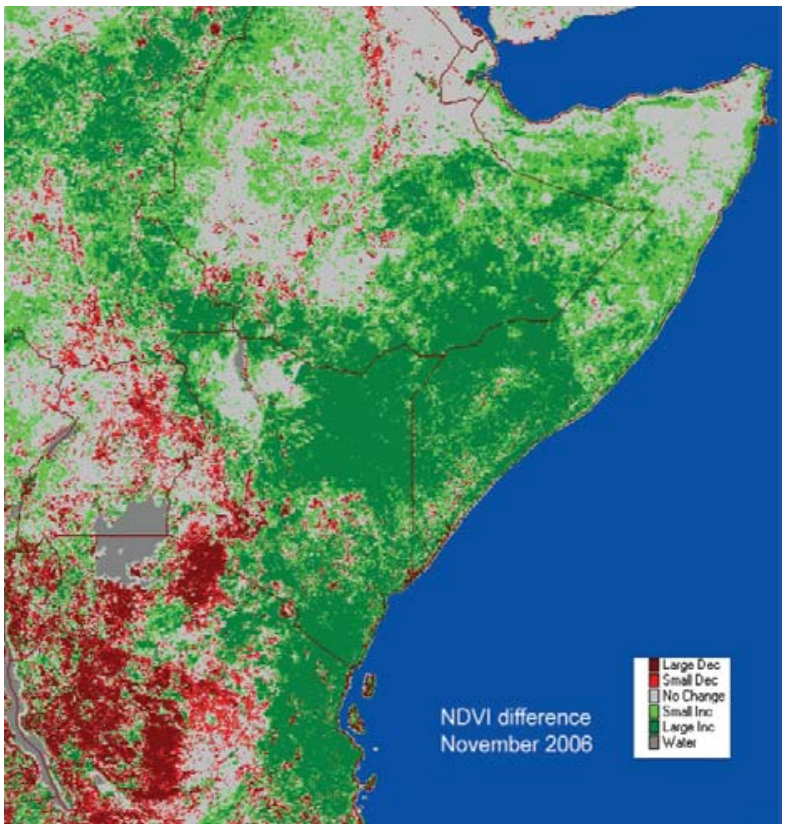

Fig. 2. NDVI anomalies in November 2006.

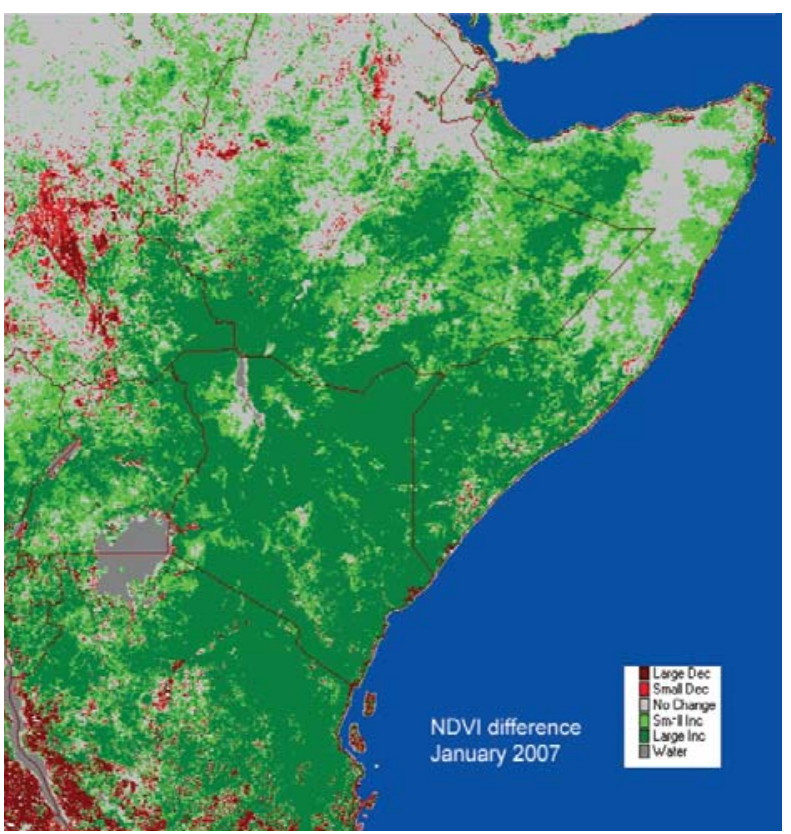

Fig. 4. NDVI anomalies in January 2007 (first decade). 


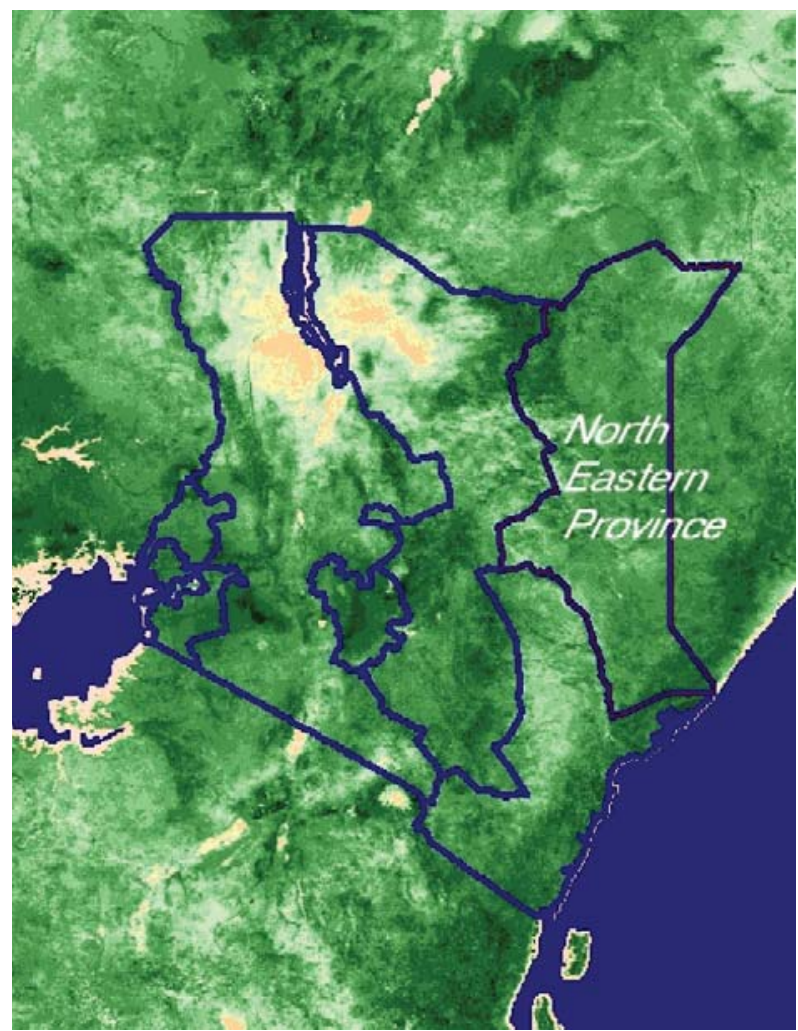

Fig. 5. Study area: North-Eastern province of Kenya. od, with probabilities as high as $55 \%$, corroborating the hypothesis that vector-borne diseases, including RVF, were likely to emerge in the region (Fig. 7).

All of these observations were consistent with the likely re-emergence of RVF in Eastern Kenya, triggered by heavy and prolonged rainfall following a long period of drought. In fact, all indicators had been on the rise for several months and were picked up by several international and regional agencies and food security programmes, including FAO, which were aware of the growing danger and alerted their respective partners. In November 2006, EMPRES issued an "EMPRES Watch" message ${ }^{2}$ that was relayed to FAO national offices, national veterinary services and research institutions.

By the end of December 2006, the first human cases of RVF were reported in the Garissa district of Kenya, rapidly followed by the detection of animal cases. The index cases of the disease occurred in the

2 EMPRES Watch: possible re-emergence of RVF in East Africa http://www.fao.org/docs/eims/upload//217874/EW_hornafrica_nov0 6_rvf.pdf

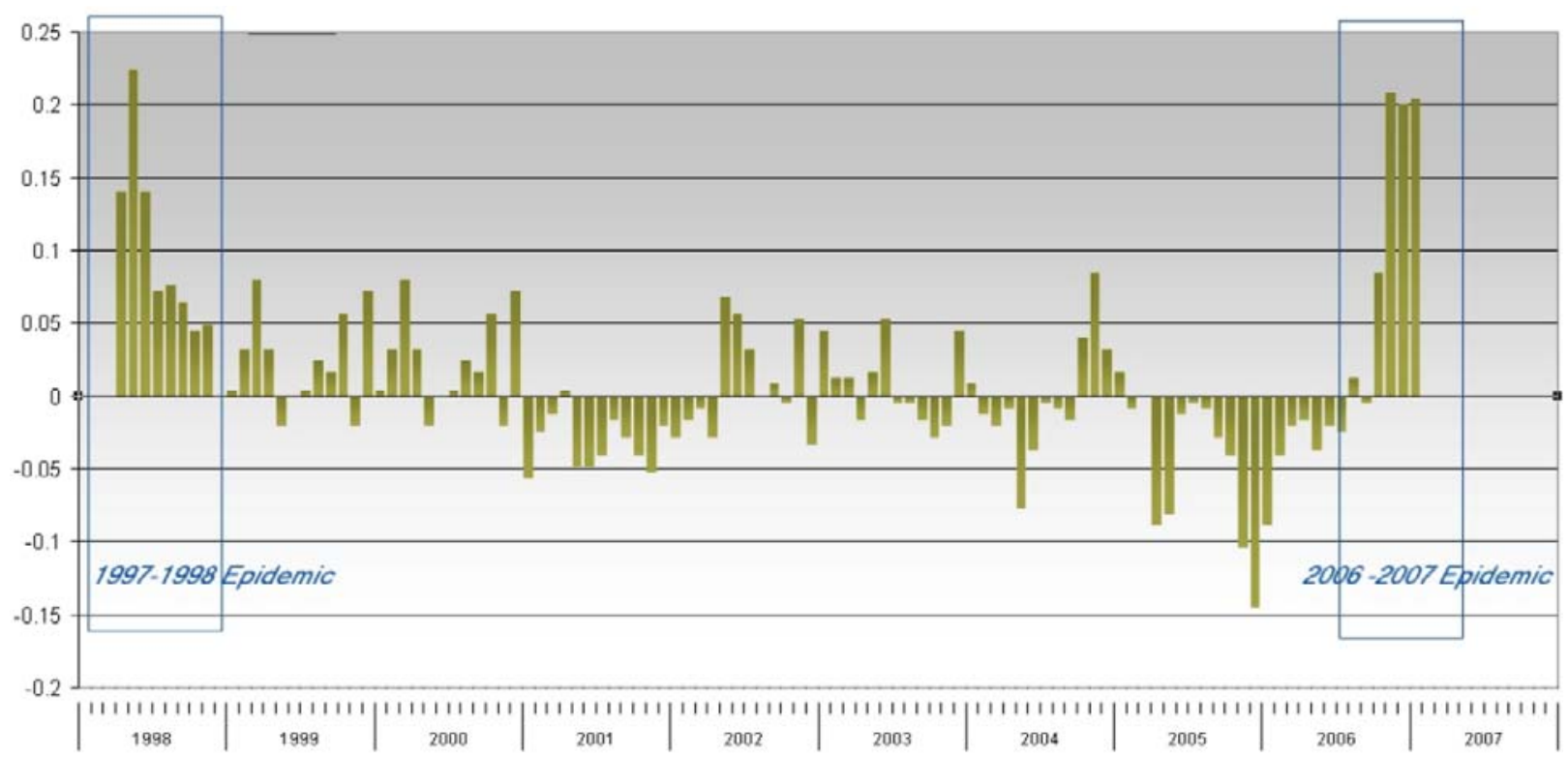

Fig. 6. NDVI anomalies for the North-Eastern province of Kenya (1998-2007). 
arid and semi-arid lowlands characterised by the presence of nomadic and semi-nomadic pastoralist systems in flood plain areas and the contiguous bushed grasslands. These areas can become flooded over hundreds of square miles and represent the best habitats and breeding sites for mosquitoes involved in RVF transmission (Fig. 8).

\section{Discussion}

One major difficulty encountered in the surveillance and the early detection of RVF lies in the comparatively low virulence of RVF virus for most of the indigenous breeds of cattle, sheep and goats kept in sub-Saharan Africa.

In Africa, high abortion rates in small ruminants remain a predominant clinical sign indicating the presence of RVF in the livestock population. As a matter of fact, due to the lack of specificity of RVF signs $^{3}$, most of the time, and notably in the recent past, an increased risk of RVF virus activity has been detected only as a result of the occurrence of human disease. This happened in the Horn of Africa in 1997-1998, in West Africa (Mauritania) in 1998 and in the Arabian Peninsula in 2000, where RVF was identified in the Eastern Rift Valley, across the Red Sea from Africa.

The ability to detect suspected cases of RVF is largely dependent upon the efficiency of national disease surveillance systems and more particularly the degree of awareness amongst field veterinary officers, technicians, extension specialists and farmers of the clinical and epidemiological features of the disease. A good knowledge of farming practices, including baseline data on husbandry practices (period of reproduction and fertility rate) and fertil-

\footnotetext{
3 Differential clinical diagnosis could include sheep or goat pox, bluetongue, foot-and-mouth disease, enterotoxaemia, peste des petits ruminats, among others. Pathological findings (i.e. massive hepatic necrosis and visceral pantropic heamorrhages) would be highly suggestive of RVF, if a post mortem examination was done, but also could endanger the examiner through contact with infected tissues or aerosolisation of the virus.
}

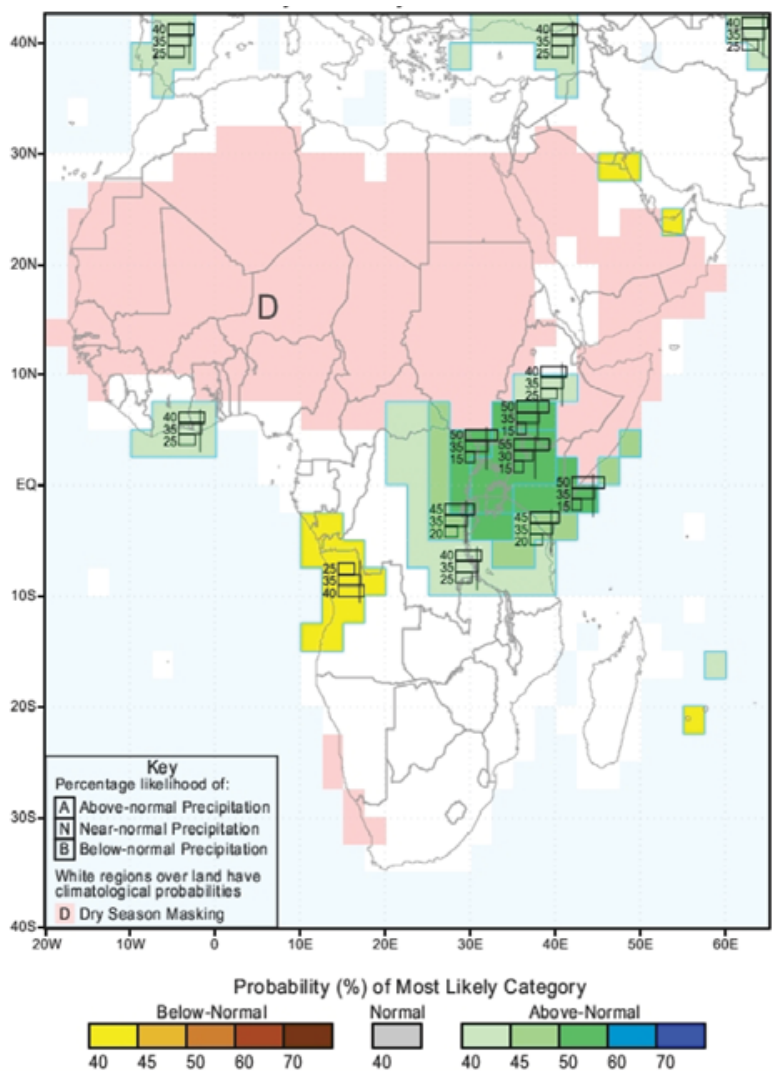

Fig. 7. IRI 3-month seasonal forecast for the period December 2006 to February 2007.

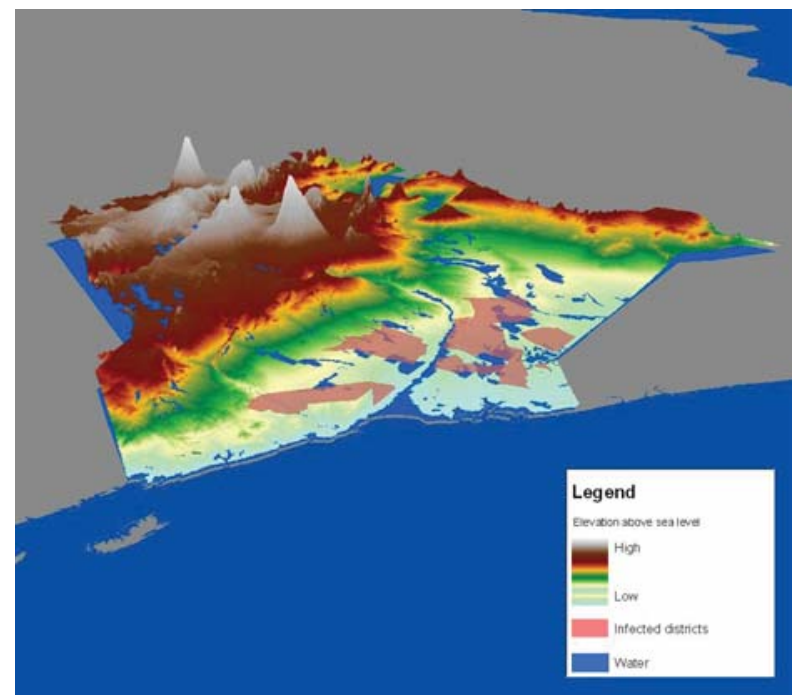

Fig. 8. 3D representation of RVF affected provinces in lowland areas of Kenya. 
ity parameters (average rate of abortions and stillbirths in local breeds) in the area is also important to provide a satisfactory quality of disease reporting. In the case of RVF, the efficacy of the system will also rely on specific targeted field surveillance activities, through the monitoring of sentinel flocks of susceptible species.

In West Africa, this has been achieved through the establishment of a specific RVF surveillance system based on the monitoring of sentinel flocks (seroconversion of susceptible animals) throughout the rainy season which is the period of increased viral amplification in the vector population, when livestock are at increased risk. Associated with the monitoring of climatic indicators, it allows national authorities to respond faster to suspected disease through improved sensitivity and specificity of disease detection.

However, the use of sentinel herds alone as a disease predictor is questionable and implies the mobilization of significant resources and manpower (dense network of sentinel herds, regular field visits, good veterinary infrastructures). The rapid delivery of laboratory results is also critical, but is often undermined by a shortage of reagents due to a lack of planning or funding. National central veterinary laboratories are sometimes unable to deliver laboratory results quickly, therefore hampering the delivery of timely alerts in case of increased viral circulation. In addition, increased incidence detection means that the disease, when the sampling was performed, has already started to circulate and spread. When sanitary authorities receive the information, it is often too late to provide a cost-effective response (i.e. vaccination). As an example, RVF outbreaks were detected in Senegal by the national surveillance system at a national level in 2003. However, the system was not sensitive enough to detect a high viral circulation associated to abortions that occurred in the Ferlo area. Moreover, the national warning was issued in November, when transhumant herds had already left the Ferlo area to return to their dry-season settlement, with subsequent disease occurrence and exposure. The cost of the whole exercise, includ- ing ear-tagging, field visits, laboratory testing and the purchase of reagents represents a serious constraint for national authorities, which sometimes cannot afford the costs involved in the implementation of such a system. Finally, during inter-epizootic periods, awareness and preparedness tend to decrease drastically and surveillance activities are redirected to other or current concerns.

To overcome the above-mentioned constraints linked to the weaknesses of sentinel herd monitoring, the use of geographical information systems (GIS) where remotely-sensed indicators known to be predictive of RVF epidemics are combined with epidemiological knowledge of the disease have proven to be successful in the prediction of RVF epidemic occurrence in East Africa. These forecasts, if accurate and delivered in a timely fashion, could help advance planning (2-3 months ahead) of targeted RVF surveillance and prophylactic activities and become a valuable tool for animal health decision makers. The prediction of a particularly wet season in specific ecological conditions could lead to the strengthening of the sentinel herd monitoring activities in high-risk areas for the detection of RVF viral circulation. In return, the forecasting of an abnormal dry season could lead to a cutback in surveillance activities with a significant decrease in the need, size or frequency of sampling.

The prediction of the RVF epidemic in Kenya in 2006-2007 indicates that the monitoring of environmental variables pertinent to vector-borne disease transmission are of increasing value in EWS, especially when combined with vulnerability assessment, and surveillance of transmission indicators. The use of disease forecasts based on RSSI has markedly increased the awareness of veterinary services and their capacity to anticipate RVF epidemics.

\section{The way forward}

In light of the recent events such as the emergence and spread of the highly pathogenic avian 
influenza, H5N1 strain or the re-emergence of RVF in East Africa in 2006, it is the responsibility of the international community to set up and implement a GLEWS for TADs. This system would aim to provide national animal health authorities with epidemiological information and warnings on the occurrence and spread of major diseases. Early knowledge is vital to provision of an adequate response in order to limit a disastrous impact; not only for the livestock that perish but also for the human population that depend on animal production for sustenance and commercial enterprises.

In the joint FAO/OIE/WHO GLEWS framework, established and launched in July 2006, there is sufficient scope for gathering and integrating agro-ecological and other information of predictive value that could function as a global EWS initiative for livestock diseases.

Establishing an EWS, based on the monitoring of environmental predictors enabling RVF prediction in time and space now appears feasible and could help to minimize its dramatic impact on livestock and human health. In a context of climate change, it is even more important to develop such EWS and extend them to other diseases of major health impacts. Following the recent pattern of El Niño/Southern Oscillation effects, the episodes of RVF may become more frequent, with shorter intervals between RVF epizootics, justifying the necessity to invest in effective national, regional and global EWS for vector-borne diseases. Climatic seasonal forecast and other predictors (NDVI, and rainfall estimates derived from satellite images) should be further validated in ecosystems where there has been no ground-truth validation exercises. These new technologies should be used by national veterinary services to overcome some of the constraints related to the maintenance of sentinel herds and intensive ground surveillance and to allow more sensitive predictions thereby enabling more cost effective and robust methods to minimize the devastation caused by such disease.

\section{References}

Anyamba A, Linthicum KJ, Mahoney R, Tucker CJ, 2002. Mapping potential risk of Rift Valley fever outbreaks in African Savannas using vegetation index time series data. Photogramm Eng Remote Sens 68, 137-145.

CDC, 1998. RVF Kenya. MMWR 47, 261-264.

Chevalier V, Lancelot R, Thiongane Y, Sall B, Mondet B, 2005. Incidence of Rift Valley fever in small ruminants in the Ferlo pastoral system (Senegal) during the 2003 rainy season. Emerg Inf Dis 11, 1693-1700.

Davies G, Martin V, 2003. Recognizing Rift Valley fever. FAO Animal Health Manual 17.

Ducheyne E, De Deken R, Bécu S, Codina B, Nomikou K, Mangana-Vougiaki O, Georgiev G, Purse BV, Hendickx G, 2007. Quantifying the wind dispersal of Culicoides species in Greece and Bulgaria. Geospatial Health 1, 177-189.

EMPRES, expert consultation, 1996. Report of the first FAO expert consultation on EMPRES, 24-26 July 1996, Rome, Italy.

Jouan A, Le Guenno B, Digoutte JP, Philippe B, Riou O, Adam F, 1988. An RVF epidemic in southern Mauritania. Ann Inst Pasteur Virol 139, 307-308.

Ksiazek TG, Jouan A, Meegan JM, Le Guenno B, Wilson ML, Peters CJ, Digoutte JP, Guillaud M, Merzoug NO, Touray EM, 1989. Rift Valley fever among domestic animals in the recent West African outbreak. Res Virol 140, 67-77.

Lancelot R, Gonzalez JP, Le Guenno B, Diallo BC, Gandega Y, Guillaud M, 1990. Descriptive epidemiology of Rift Valley fever in small ruminants in Southern Mauritania after the 1988 rainy season. Rev Elev Med Vet Pays Trop 42, 485-491 (in French).

Linthicum KJ, Anyamba A, Tucker CJ, Kelley PW, Myers MF, Peters CJ, 1999. Climate and satellite indicators to forecast Rift Valley fever epidemics in Kenya. Science 285, 397-400. Linthicum KJ, Bailey CL, Davies FG, Tucker CJ, 1987. Detection of Rift Valley fever viral activity in Kenya by satellite remote sensing imagery. Science 235, 1656-1659.

Linthicum KJ, Bailey CL, Tucker CJ, Mitchell KD, Logan TM, Davies FG, Kamau CW, Thande PC, Wagateh JN, 1990. Application of polar-orbiting, meteorological satellite data to detect flooding of Rift Valley fever virus vector mos- 
quito habitats in Kenya. Med Vet Entomol 4, 433-438.

Nabeth P, Kane Y, Abdalahi MO, Diallo M, Ndiaye K, Ba K, Schneegans F, Sall AA, Mathiot C, 2001. Rift Valley fever outbreak, Mauritania, 1998: seroepidemiologic, virologic, entomologic, and zoologic investigations. Emerg Infect Dis 7, 1052-1054.

Saluzzo JF, Chartier C, Bada R, Martinez D, Digoutte JP, 1987. Rift Valley fever in Western Africa. Rev Elev Med Vet Pays Trop 40, 215-223 (in French).
Soti V, Chevalier V, Maura J, Tran AL, Etter E, Lelong C, Sow D, Ndiaye M, Sall B, Thiongane Y, Lancelot R, De la Rocque S, 2007. Landscape characterization of Rift Valley Fever risk areas using very high spatial resolution imagery: case study in the Ferlo area, Senegal. Proceedings of the GISVet Conference, 20-24 August 2007, Copenhagen, Denmark.

WHO, 1998. Rift Valley fever in Kenya and Somalia. Update 2. Disease Outbreak Reported. 